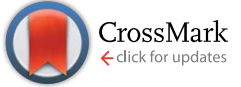

Cite this: RSC Adv., 2017, 7, 12511

Received 11th January 2017

Accepted 15th February 2017

DOI: $10.1039 / c 7 r a 00449 d$

rsc.li/rsc-advances

\section{Composition-controlled synthesis and tunable optical properties of ternary boron carbonitride nanotubes $\dagger$}

\author{
Hongling Li,,$^{\mathrm{a}}$ Roland Yingjie Tay,,$^{\mathrm{ab}}$ Siu Hon Tsang, ${ }^{\mathrm{b}}$ Lin Jing, ${ }^{\mathrm{c}}$ Minmin Zhu, ${ }^{a}$ \\ Fei Ni Leong ${ }^{a}$ and Edwin Hang Tong Teo*ac
}

Controlling the composition and structure of boron carbonitride nanotubes (BCNNTs) is the critical factor for tuning their electrical and optical properties, which in turn allows for the broadening of their applications. However, most of the known methods for synthesizing BCNNTs employ toxic precursors at high temperatures (up to $2000^{\circ} \mathrm{C}$ ) and the achieved BCNNTs usually encounter phase-separation of BN and C. Herein, a facile large-scale synthesis of ternary BCNNTs with controllable composition by a chemical vapor deposition process at a relatively low temperature of $900{ }^{\circ} \mathrm{C}$ is reported. By simply adjusting the synthetic parameters, BCNNTs with two different atomic ratios of B : C : N can be successfully synthesized. Their morphologies and ternary structure as well as optical properties are further investigated. Notably, the asprepared BNCNTs-50 are stable up to $900{ }^{\circ} \mathrm{C}$ in air and exhibit an optical band gap of $\sim 4.36 \mathrm{eV}$. The results demonstrated in this study will open new avenues for a variety of potential applications of BCNNTs in electronics, photonics, sensors and high temperature lubricants.

\section{Introduction}

Boron carbonitride (BCN), one type of advanced lightweight material, has been intensively studied over the last few decades. ${ }^{\mathbf{1 1 1}}$ Particularly, BCN nanotubes (BCNNTs) have been actively pursued due to their outstanding physiochemical characteristics such as semiconductivity, ${ }^{1-7}$ high resistance to oxidation at temperatures up to $900{ }^{\circ} \mathrm{C}$ in air, ${ }^{5}$ and excellent mechanical performance. ${ }^{6,8}$ Previous studies have shown that they are promising candidates for applications in electronics and high temperature lubricants. ${ }^{12-14}$ Unlike carbon nanotubes (CNTs), the optical and electronic properties of BCNNTs can be altered by simply adjusting the composition rather than their geometrical structure, which is relatively easy and practical. ${ }^{6,15-17}$ To date, many efforts have been devoted to the synthesis of BCNNTs ${ }^{4,15,18}$ such as arc-discharge, ${ }^{12,19-21}$ laser ablation, ${ }^{22}$ pyrolysis, ${ }^{23-25}$ chemical vapor deposition (CVD) ${ }^{5,7,14,26-32}$ and substitution reaction. ${ }^{33-38}$ Among them, CVD, which has been verified as a more advanced and easiest technique for the synthesis of boron nitride nanotubes (BNNTs), is expected to be promising approach for the preparation of BCNNTs with various

${ }^{a}$ School of Electrical and Electronic Engineering, Nanyang Technological University, 50 Nanyang Avenue, Singapore 639798, Singapore.E-mail: htteo@ntu.edu.sg

${ }^{b}$ Temasek Laboratories@NTU, 50 Nanyang Avenue, Singapore 639798, Singapore

${ }^{c}$ School of Materials Science and Engineering, Nanyang Technological University, 50 Nanyang Avenue, Singapore 639798, Singapore

$\dagger$ Electronic supplementary information (ESI) available. See DOI: 10.1039/c7ra00449d

\$ These two authors contribute equally to this work. microstructures and chemical compositions by adjusting the growth parameters. ${ }^{39,40}$ However, most of the known methods to achieve such BCNNTs have to employ toxic precursors such as $\mathrm{B}_{2} \mathrm{H}_{2}, \mathrm{~B}_{2} \mathrm{H}_{6}, \mathrm{BCl}_{3}$ and $\mathrm{BH}_{3}$-trimethylamine adduct at very high temperatures up to $2000{ }^{\circ} \mathrm{C}^{25,26}$ In addition, various reported BCNNTs still encounter the phase-separation of BN and C. ${ }^{15,19,21}$ Moreover, it is noted that $\mathrm{C}$ species are the dominant components for most of the previously reported BCNNTs, while BCNNTs with higher percentages of $\mathrm{B}$ and $\mathrm{N}$ species which show promising electronic and magnetic properties are still lacking. ${ }^{41}$ Therefore, considerable research efforts are still needed to explore synthetic methodologies to obtain BCNNTs with controllable composition and exceptional physicochemical properties.

Benefiting from the structural similarity between BCNNTs and CNTs, it is suggested that B and N species can be smoothly incorporated into the CNT structure by substituting $\mathrm{C}$ atoms. ${ }^{33-36}$ As reported, the surface of pristine CNTs is generally not reactive and $\mathrm{BCN}$ nanotubes could be synthesized by employing amorphous CNTs as starting materials. ${ }^{35}$ Recently, we also found that hydroxyl groups and defects introduced by the aid of $\mathrm{O}_{2}$ plasma could improve the nucleation of $\mathrm{BN}$ on the surface of the CNTs. ${ }^{42}$ Therefore, it is expected that the introduction of hydroxyl groups and defects onto the surface of the CNTs will further facilitate the substitution reaction at a relatively low temperature and promote the formation of BCNNTs with high $\mathrm{B}$ and $\mathrm{N}$ concentrations.

In this study, we report for the first time a facile strategy for large-scale synthesis of ternary BCNNTs with high $\mathrm{B}$ and $\mathrm{N}$ concentrations at a relatively low temperature of $900{ }^{\circ} \mathrm{C}$ by 
employing the acid-treated CNTs as the starting materials. By altering the flow rate of ammonia, two types of BCNNTs (different atomic ratios of $\mathrm{B}: \mathrm{C}: \mathrm{N}$ ) are successfully prepared. In addition, their morphologies, microstructures, chemical compositions, bonding states as well as the thermal and optical properties are systematically investigated. It is noted that the asprepared BCNNTs are stable up to $900{ }^{\circ} \mathrm{C}$ in air and exhibit an optical band gap of $4.36 \mathrm{eV}$. The results could shed new light on the development in the BCNNTs with controllable composition and benefit their potential applications.

\section{Experimental section}

\section{Materials}

Acid-treated MWCNT (BU-201) was purchased from Bucky USA. All chemicals were used as received without further purification.

\section{Synthesis of BCNNTs}

Acid-treated CNTs were loaded into the centre of a horizontal quartz tube and solid boric acid located at a lower temperature zone was chosen as a boron source. Ammonia gas was used as a source of nitrogen. Firstly, the temperature of the furnace was slowly ramped to $830^{\circ} \mathrm{C}$ in an argon atmosphere. After that, boric acid vapour resulting from heating the solid boric acid at a temperature of $\sim 300{ }^{\circ} \mathrm{C}$ and the ammonia gas with a flow rate of $50 \mathrm{sccm}$ were simultaneously introduced into the system. After being kept at $830{ }^{\circ} \mathrm{C}$ for $30 \mathrm{~min}$, the temperature was raised to $900{ }^{\circ} \mathrm{C}$ and kept at $900{ }^{\circ} \mathrm{C}$ for $1 \mathrm{~h}$. In order to remove the residual carbon materials, the products were treated at $630{ }^{\circ} \mathrm{C}$ under the ambient conditions for $1 \mathrm{~h}$ to yield as-produced BCNNTs (herein referred to as BCNNTs-50). The doping level of $\mathrm{BN}$ can be controlled by varying the flow rate of ammonia gas and the as-prepared BCNNTs was generated as BCNNTs-100 when $100 \mathrm{sccm}$ ammonia gas was used.

\section{Characterization}

Scanning electron microscopy (SEM, LEO 1550 Gemini) and transmission electron microscopy (TEM, Tecnai G2 F20 X-Twin) were used to characterize the morphology and microstructure of the CNTs and as-prepared BCNNTs. The electron energy-loss spectroscopy (EELS) and X-ray photoelectron spectroscopy (XPS, VG ESCA 220i-XL Imaging) were used to determine the chemical composition and bonding structure of the nanotubes. Fourier transform infrared (FT-IR) spectra were collected on an IRPrestige-21 spectrometer in $\mathrm{KBr}$ media within the wavenumber ranging from 4000 to $400 \mathrm{~cm}^{-1}$. All the samples were thoroughly dried before measurements. Thermogravimetric analysis (TGA, Shimadzu DTG-60H thermal analyzer) was carried out under a constant flow of air $\left(50 \mathrm{~mL} \mathrm{~min}^{-1}\right)$ and heated from 30 to $1100{ }^{\circ} \mathrm{C}$ at a heating rate of $10{ }^{\circ} \mathrm{C} \mathrm{min}^{-1}$. Ultraviolet-visible spectroscopy (UV-vis, Shimadzu UV-2450) was used to extract the optical band gaps (OBGs) of the BCNNTs. Raman spectra were collected with a WITEC CRM200 Raman System (532 nm laser, $2.54 \mathrm{eV}$, WITec, Germany).

\section{Results and discussion}

Fig. 1 shows the morphologies and microstructures of the starting CNTs and the as-synthesized BCNNTs samples. Typical SEM (Fig. 1a-c) and low-resolution TEM (Fig. 1d-f) images of nanotube bundles reveal that the BCNNTs-50 and BCNNTs-100 are up to several micrometres in length and several nanometres in diameter, which are similar to those of the starting CNTs. High-resolution TEM images show that the starting CNTs exhibit an inner diameter of $4.82 \mathrm{~nm}$ with an average wall thickness of $\sim 4.33 \mathrm{~nm}$ (corresponding to 12-13 C layers, Fig. 1g), ${ }^{43}$ while an evident increase in the inner diameter and decrease in the wall thickness are observed for both the asprepared BCNNTs-50 (with an inner diameter of $8.67 \mathrm{~nm}$ and an average wall thickness of $\sim 1.78 \mathrm{~nm}$, corresponding to 5-6 BCN layers, Fig. 1h) and BCNNTs-100 samples (with an inner diameter of $7.23 \mathrm{~nm}$ and an average wall thickness of $\sim 2.05 \mathrm{~nm}$, corresponding to 5-6 BCN layers, Fig. 1i). ${ }^{44}$ It is noted that both the starting acid-treated CNTs and the as-prepared BCNNTs exist as multi-walled structures, while the CNTs have over twice as many layers as the BCNNTs. This is because that compared with pure CNTs, the starting acid-treated CNTs have more defects and hydroxyl groups on the outermost tube shells. ${ }^{\mathbf{3 3 , 4 2}}$ These defects and hydroxyl groups will provide many more accessible active surface sites in the nanotube lattice structure, which are advantageous for the substitution reaction. ${ }^{42}$ Therefore, the presence of defects and hydroxyl groups encourages the BCN layers to form mainly on the outermost shells. These BCN outermost shells are stable and well preserved after our annealing process in which a high temperature of $630{ }^{\circ} \mathrm{C}$ was used. In addition, the lattice fringes can be clearly seen for both the BCNNTs-50 and BCNNTs-100 and the interlayer spacing is approximately $0.343 \mathrm{~nm}$, which is in good agreement with the (002) planes of the hexagonal system of B-C-N and is further verified by Raman spectroscopy. ${ }^{45}$ Similar to previous studies, ${ }^{3,20}$ the Raman scattering features of the ternary BCN nanotubes have a resemblance with those of starting CNTs, while with broadened D and G bands (Fig. S1 $\dagger$ ). This Raman band broadening is mainly due to the high $\mathrm{B}$ and $\mathrm{N}$ atomic concentrations in the as-prepared BCN nanotubes. ${ }^{46}$

The hybrid structure of the as-synthesized BCNNTs-50 and BCNNTs-100 nanotubes can be verified by EELS elemental mapping profiles (Fig. 2a-f). The typical elemental mapping of $\mathrm{B}$, $\mathrm{C}$ and $\mathrm{N}$ for BCNNTs-50 (Fig. 2a-c) and BCNNTs-100 (Fig. 2d-f) bundles strongly support that the $\mathrm{B}, \mathrm{C}, \mathrm{N}$ are uniformly distributed in the BCNNT tube layers. Fig. $2 \mathrm{~g}$ shows EELS spectra of CNT and as-synthesized BCNNT nanotubes. For CNTs, typical ionization edge of $\mathrm{C}$ is observed at $284 \mathrm{eV}$, corresponding to characteristic K-shell ionization edge of C. ${ }^{47}$ For BCNNTs-50 and BCNNTs-100, besides typical C peak which becomes much weaker, another two characteristic ionization edges are observed at around 188 and $401 \mathrm{eV}$, corresponding to the characteristic Kshell ionization edges of $\mathrm{B}$ and $\mathrm{N}$, respectively. ${ }^{5,33,44}$ The two pronounced peaks for the B K-edge at about 191 and $197 \mathrm{eV}$, confirming the $\mathrm{sp}^{2}$ hybridization state of $\mathrm{B}$ atoms. ${ }^{5}$ Although observed relatively weaker, the $\mathrm{C}$ K-edge also shows discernible 

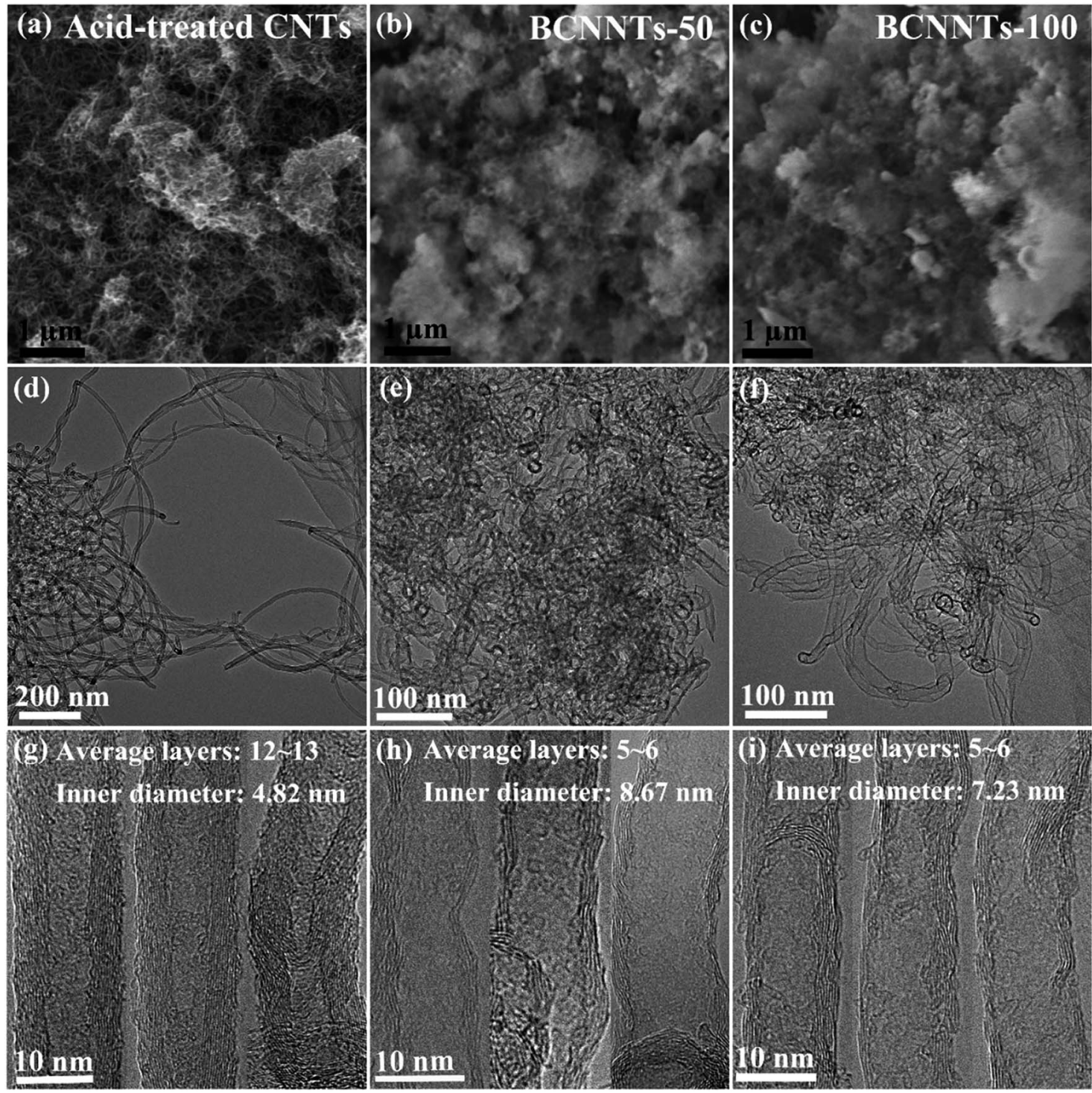

Fig. 1 (a-c) SEM, (d-f) low-resolution and ( $g-i)$ high-resolution TEM images of acid-treated $(a, d$ and g) CNTs, (b, e and h) BCNNTs-50 and (c, $f$ and i) BCNNTs-100 samples.

$\pi^{*}$ peak as well as $\sigma^{*}$ band, indicating that $\mathrm{C}$ atoms are in the same $\mathrm{sp}^{2}$-hybridized state as their $\mathrm{BN}$ counterparts while at a lower concentration. ${ }^{45}$ That is, the $\mathrm{B}$ and $\mathrm{N}$ atoms have been successfully built into the graphite network by substitutional doping, rather than gathered in the bundle intra-tube or outertube layers. ${ }^{14}$ The extracted atomic $\mathrm{B} / \mathrm{C} / \mathrm{N} / \mathrm{O}$ ratios from the EELS measurements are 0.40/0.12/0.40/0.08 and 0.45/0.03/0.43/ 0.09 for typical BCNNTs-50 and BCNNTs-100 nanotube bundles, respectively, suggesting that $\mathrm{B}$ and $\mathrm{N}$ elements prefer to incorporate into the network of the nanotubes in the ratio of $1: 1$.

XPS analysis is employed to further identify the ternary bonding nature of BCNNTs-50 and BCNNTs-100. As shown in the typical XPS survey spectra (Fig. 3a), peaks corresponding to $\mathrm{B} 1 \mathrm{~s}$ and $\mathrm{N} 1 \mathrm{~s}$ are found only in the BCNNTs-50 and BCNNTs100 samples besides the $\mathrm{C} 1 \mathrm{~s}$ and $\mathrm{O} 1 \mathrm{~s}$ peaks. The existence of $\mathrm{O} 1 \mathrm{~s}$ peak around $532 \mathrm{eV}$ for CNTs and BCNNTs are attributed to the partial oxidation of the CNTs and BCNNTs during the acid-treatment and annealing processes, respectively. ${ }^{48}$ The high-resolution C 1s spectrum for CNTs given in Fig. 3b could be deconvoluted into three peaks at 284.4, 285.8, and $287.2 \mathrm{eV}$, arising from the $\mathrm{C}-\mathrm{C}, \mathrm{C}-\mathrm{O}$ and $\mathrm{C}=\mathrm{O}$ bonds, respectively. The relatively broad peaks of $\mathrm{B} 1 \mathrm{~s}, \mathrm{C} 1 \mathrm{~s}$ and $\mathrm{N} 1 \mathrm{~s}$, imply that the existence of multiple chemical environments in the BCNNTTs50 and BCNNTs-100 samples (Fig. 3c-h). The high-resolution $B$ 1s peak in Fig. $3 \mathrm{c}$ and $\mathrm{f}$ could be fitted with three peaks at 189.3, 190.7 and $192.0 \mathrm{eV}$, attributing to B-N, B-O and B-C bonds, respectively. ${ }^{5,49}$ The relatively higher intensity for the $\mathrm{B}-$ N/B-C in both BCNNTs-50 and BCNNTs- 100 samples indicate that a greater number of $\mathrm{B}$ species are attached to $\mathrm{N}$ in the network. As shown in Fig. 3d and g, the four deconvoluted peaks in the C 1s spectrum located at 283.3, 284.4, 286.0 and $288.5 \mathrm{eV}$ corresponds to C-B, C-C, C-N and C-O bonds, respectively. ${ }^{5,49} \mathrm{It}$ is noted that the percentage of $\mathrm{C}$ bonded to $\mathrm{N}$ is higher than that 

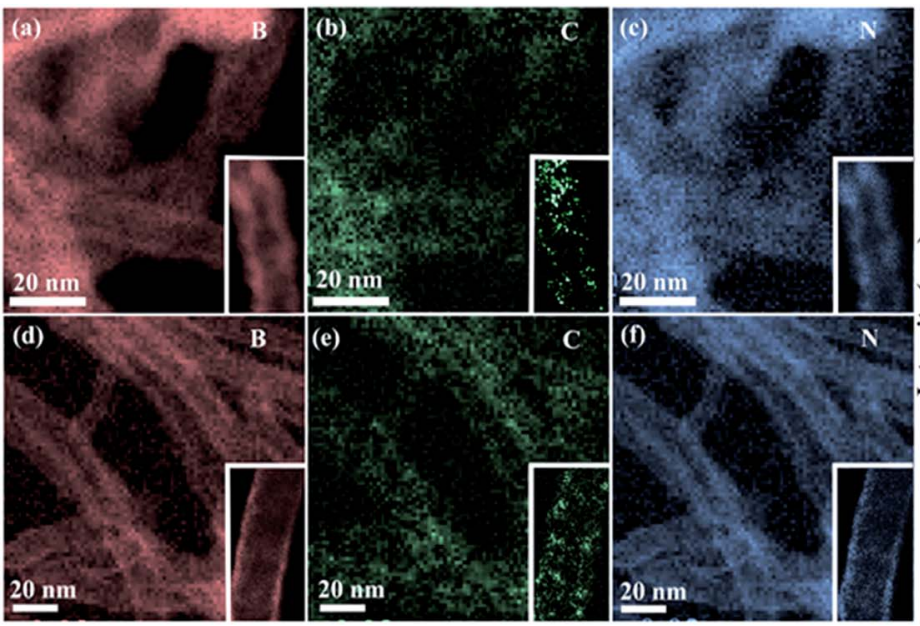

(g)
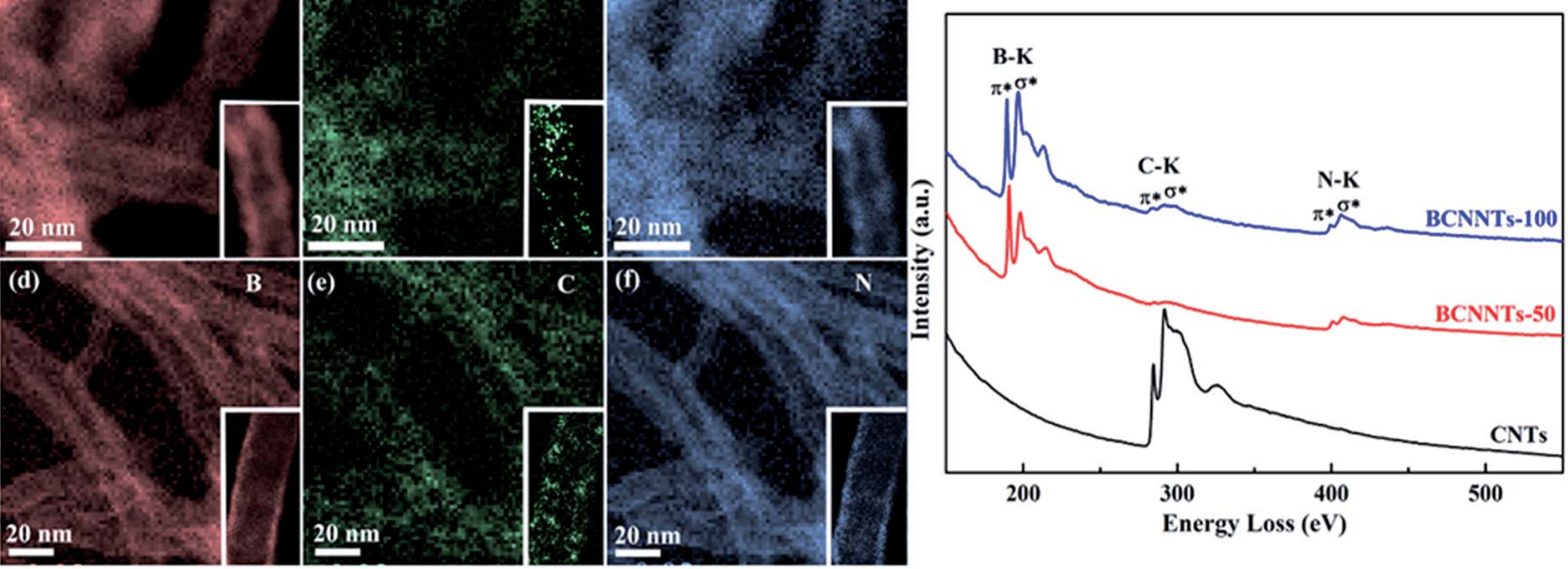

Fig. 2 EELS elemental mapping taken from (a-c) BCNNTs-50 and (d-f) BCNNTs-100 bundles, respectively. The insets of (a-f) show the corresponding element mapping of an individual tube, respectively, implying the uniform distribution of the $B, C$, and $N$ species in the nanotubes. (g) Representative EELS spectra taken from individual CNT, BCNNTs-50 and BCNNTs-100 samples, respectively, revealing the dominating composition of $\mathrm{B}, \mathrm{C}$ and $\mathrm{N}$ elements in the BCNNTs-50 and BCNNTs-100 samples.

of $\mathrm{C}$ bonded to $\mathrm{B}$ or $\mathrm{O}$ for BCNNTs-50 sample, while the percentage of $\mathrm{C}$ bonded to $\mathrm{B}$ is significantly higher than that of $\mathrm{C}$ bonded to $\mathrm{N}$ or $\mathrm{O}$ for BCNNTs-100 sample, attributable to the difference in the ammonia gas amount introduced. The highresolution $\mathrm{N}$ 1s peaks in Fig. 3e and h show mainly three subpeaks at $396.8,398$, and $399.9 \mathrm{eV}$, corresponding to the $\mathrm{N}-\mathrm{B}$,
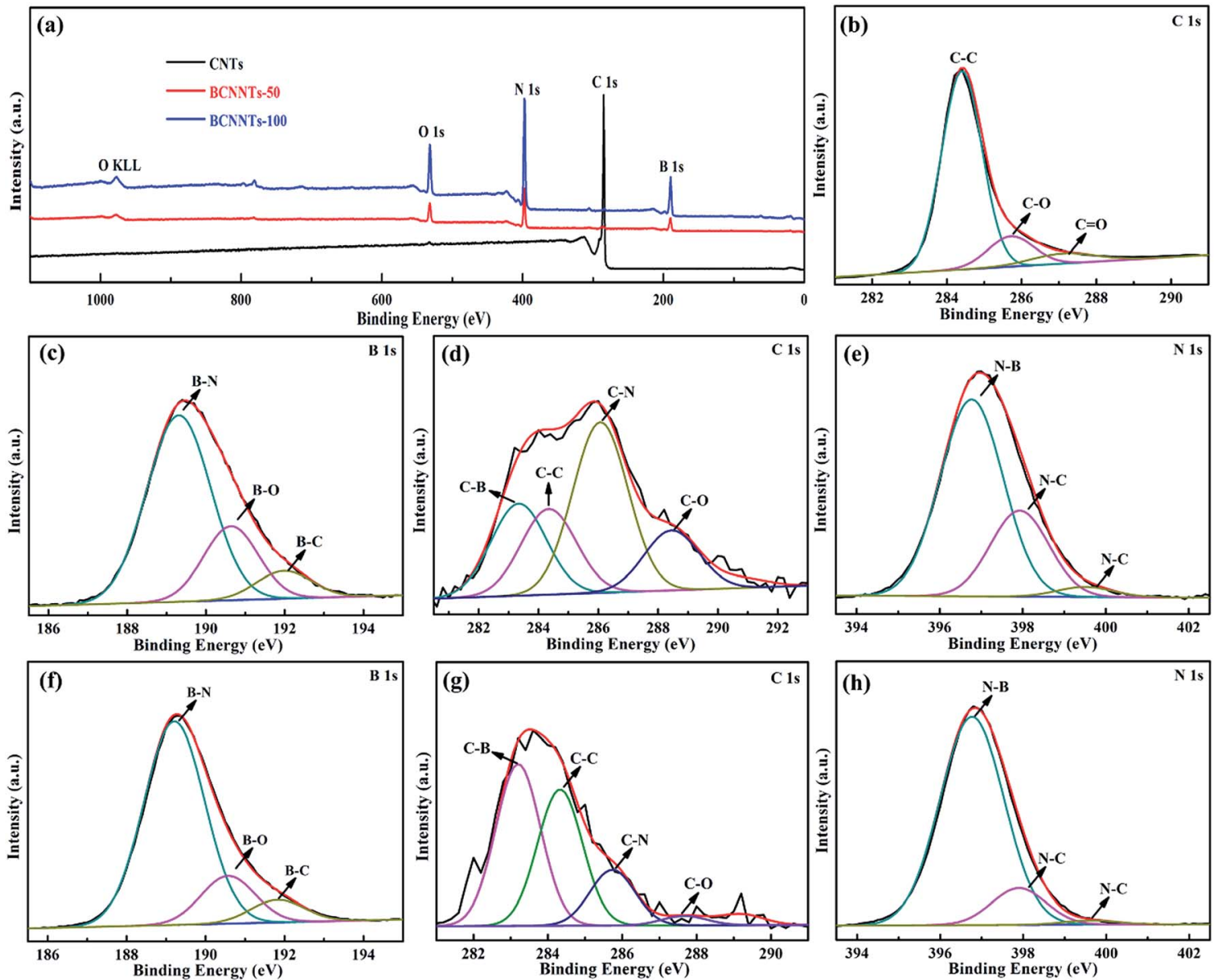

Fig. 3 Chemical composition and bonding structure of CNTs, BCNNTs-50 and BCNNTs-100 samples through XPS studies. (a) Survey spectra. Typical high-resolution spectra for (b) CNTs, (c-e) BCNNTs-50 and (f-h) BCNNTs-100, respectively. 
graphitic $\mathrm{N}-\mathrm{C}$ and pyridinic $\mathrm{N}-\mathrm{C}$ bonds, respectively. The amount of pyridinic $\mathrm{N}$ is relatively smaller than that of the graphitic $\mathrm{N}$ and the relatively higher intensity of the $\mathrm{N}-\mathrm{B}$ peak than that of $\mathrm{N}-\mathrm{C}$ indicate that a greater number of $\mathrm{N}$ are attached to $\mathrm{B}$ in the network. These XPS results together with the TEM/EELS analysis suggest that $\mathrm{B}, \mathrm{N}$, and $\mathrm{C}$ atoms are chemically bonded with each other.

To further investigate the type and nature of the chemical bonds in the starting CNTs and the achieved BCNNTs samples, FT-IR measurements are performed (Fig. 4a). As for the starting CNTs, a broad absorption band is observed at $\sim 3430 \mathrm{~cm}^{-1}$, due to the presence of $-\mathrm{OH}$ groups, which is consistent with the XPS results mentioned above. For both the BCNNTs-50 and BCNNTs100 samples, aside from the broad absorption band at $\sim 3430$ $\mathrm{cm}^{-1}$ which is attributed to $\mathrm{O}-\mathrm{H}$ or $\mathrm{N}-\mathrm{H}$ bonds, ${ }^{48}$ the appearance of other new absorption peaks can be clearly identified. The broad strong absorption peak at $\sim 1392 \mathrm{~cm}^{-1}$ and the peak at $\sim 809$ $\mathrm{cm}^{-1}$ can be attributed to the in-plane stretching and out-of-plane bending vibration of $\mathrm{B}-\mathrm{C}-\mathrm{N}$ rings, respectively. ${ }^{50}$ Meanwhile, the peaks appeared at $\sim 1171$ and $1279 \mathrm{~cm}^{-1}$ can be assigned to the stretching vibration of boron-rich and carbon-rich $\mathrm{B}-\mathrm{C}$ bonds (or the stretching vibration of $\mathrm{sp}^{2} \mathrm{C}-\mathrm{N}$ bonds), respectively. The FT-IR results determine the presence of $\mathrm{B}-\mathrm{N}, \mathrm{B}-\mathrm{C}, \mathrm{C}-\mathrm{N}$ and $\mathrm{C}-\mathrm{C}$ bonds in a hexagonal network, further confirming the XPS results and the model presenting the hybridized structure of the BCNNTs.
Having inspected the chemical composition and bonding structure of the starting CNTs and as-prepared BCNNTs samples, we further investigate their thermal stabilities and optical properties. Fig. 4b shows the thermogravimetric analysis (TGA) of the starting CNTs and the as-prepared BCNNTs. Both BCNNTs-50 and BCNNTs-100 are found to be almost stable up to $900{ }^{\circ} \mathrm{C}$ in air, while the CNTs almost totally decomposed around $600{ }^{\circ} \mathrm{C}$. It is observed that the thermal stability of the as-prepared BCNNTs is higher than that of carboxylate-functionalized BNNTs, ${ }^{3}$ and comparable to those of vertically aligned $\mathrm{BCN}^{5}$ and $\mathrm{BC}_{4} \mathrm{~N}$ nanotubes. ${ }^{35}$

The optical absorption properties display the electronic state of a material and can be used to verify the band gap of semiconductors. UV-vis absorption spectroscopy is utilized to investigate the optical energy gap $\left(E_{\mathrm{g}}\right)$ of the synthesized BCNNTs based on the following Tauc's formulation: ${ }^{51}$

$$
\alpha=C\left(E-E_{\mathrm{g}}\right)^{1 / 2} / E
$$

where $\alpha$ is the absorption coefficient, $C$ is a constant and $E$ is the photon energy. Note that $\alpha$ is obtained from the optical absorption divided by the length of the nanotubes. ${ }^{52}$ Hence, by plotting $(\alpha E)^{2}$ against $E$, a straight line can be extrapolated on the energy dispersion curve and $E_{\mathrm{g}}$ can be extracted from the intersection of the extrapolated line and the $x$-axis. Fig. $4 \mathrm{c}$ shows the UV-vis absorption spectra of the BCNNTs-50 and
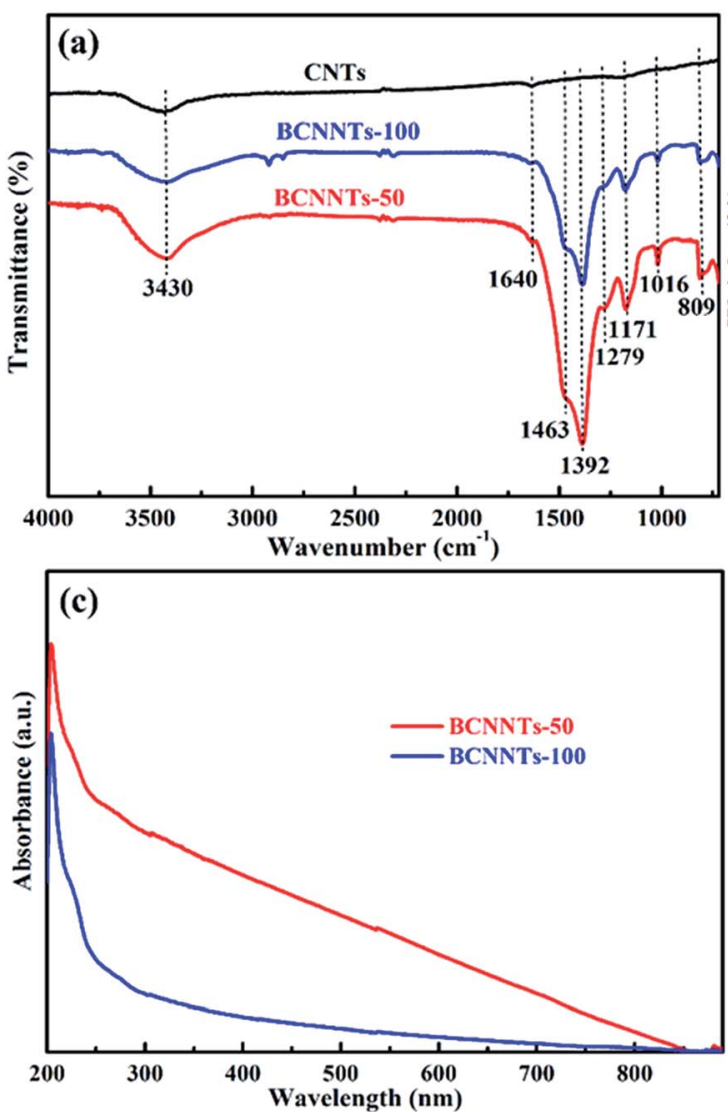
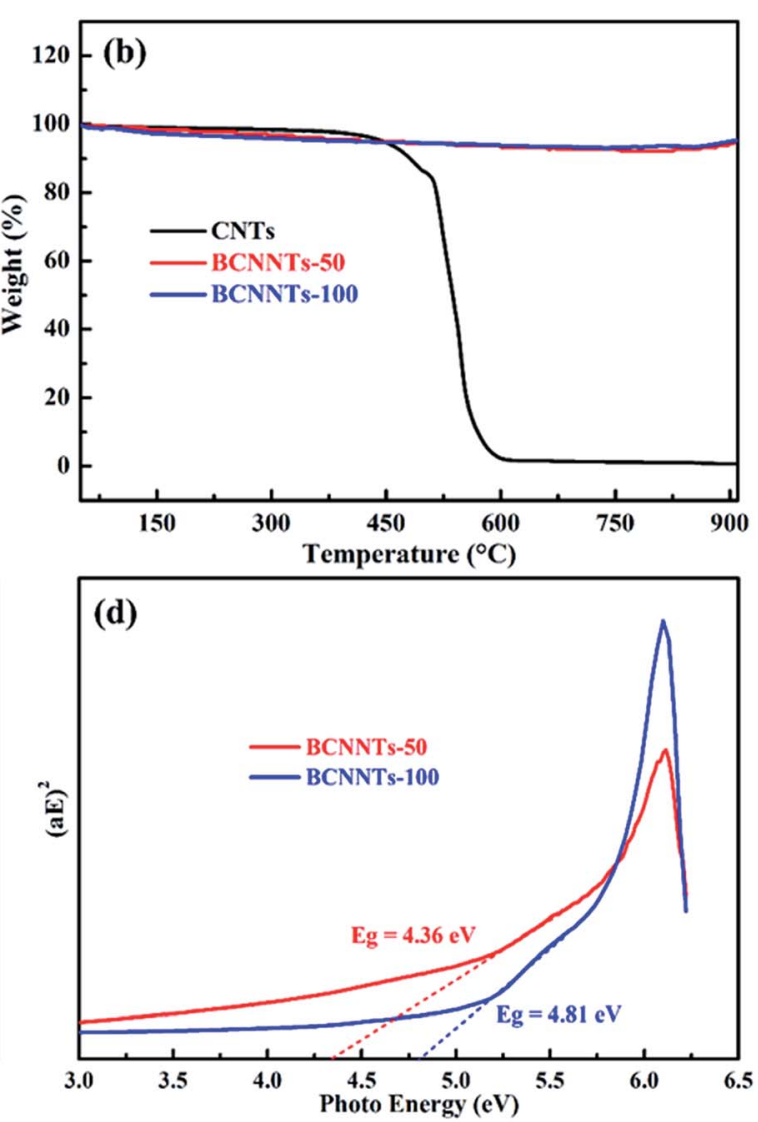

Fig. 4 (a) FT-IR spectra and (b) TGA profiles of CNTs and as-prepared BCNNTs. (c) UV-vis absorption spectra of BCNNTs-50 and BCNNTs-100. (d) Tauc's plots based on the optical absorption data from BCNNTs-50 and BCNNTs-100, respectively. 
BCNNTs-100. The broad absorption peak ranging from 200 to $850 \mathrm{~nm}$ is observed for the BCNNTs samples, corresponding to an optical band gap of $\sim 4.36$ and $4.81 \mathrm{eV}$, respectively (Fig. 4d). These band gaps are obviously smaller than that of reported BNNTs which exhibited a wide band gap of up to $5.9 \mathrm{eV}$, attributive to the incorporation of $\mathrm{C}$ components in the $\mathrm{BN}$ domains., ${ }^{2,53}$ Observing only a single optical band gap in BCNNTs samples indicates that they are mainly composed of single-phase hybrid domains of BCN. Based on the abovementioned results, it is possible that BCNNTs with various BN doping level and properties can be prepared by changing the growth parameters such as the boric acid amount/ratio, temperature, and the growth duration as well as the subsequent annealing temperature and time.

\section{Conclusions}

In summary, we have successfully developed a facile route based on a CVD technique to fabricate BCNNTs with high $\mathrm{B}$ and $\mathrm{N}$ concentrations at a relatively low temperature of $900{ }^{\circ} \mathrm{C}$. By varying the amount of ammonia, BCNNTs with two different compositions with an average wall thickness of $\sim 5-6$ layers are successfully prepared. Notably, the as-prepared BCNNTs exhibit excellent thermal stability and are stable up to $900{ }^{\circ} \mathrm{C}$ in air. Furthermore, the as-prepared BCNNTs-50 and BCNNTs-100 samples show an optical band gap of $\sim 4.36$ and $4.81 \mathrm{eV}$, respectively, which makes them promising materials for further fundamental physical studies and potential applications in optoelectronics.

\section{Acknowledgements}

We acknowledge the funding support from the Singapore Ministry of Education Academic Research Fund Tier 2 No. MOE2013-T2-2-050.

\section{Notes and references}

1 Y. B. Yan, J. W. Miao, Z. H. Yang, F. X. Xiao, H. B. Yang, B. Liu and Y. H. Yang, Chem. Soc. Rev., 2015, 44, 3295.

2 D. Golberg, Y. Bando, Y. Huang, T. Terao, M. Mitome, C. C. Tang and C. Y. Zhi, ACS Nano, 2010, 4, 2979.

3 W. L. Wang, Y. Bando, C. Y. Zhi, W. Y. Fu, E. G. Wang and D. Golberg, J. Am. Chem. Soc., 2008, 130, 8144.

4 D. Jana, C.-L. Sun, L.-C. Chen and K.-H. Chen, Prog. Mater. Sci., 2013, 58, 565.

5 E. Iyyamperumal, S. Wang and L. Dai, ACS Nano, 2012, 6, 5259.

6 J. Garel, C. Zhao, R. Popovitz-Biro, D. Golberg, W. Wang and E. Joselevich, Nano Lett., 2014, 14, 6132.

7 S. Wang, E. Iyyamperumal, A. Roy, Y. Xue, D. Yu and L. Dai, Angew. Chem., Int. Ed., 2011, 50, 11756.

8 E. Hernandez, C. Goze, P. Bernier and A. Rubio, Phys. Rev. Lett., 1998, 80, 4502.

9 S. Jeon, W. Song, M. J. Cha, I. Song, Y. Kim, S. H. Kim and C. Y. Park, J. Korean Phys. Soc., 2013, 63, 1152.

10 Y. Zhou, F. M. Gao, W. F. Guo and L. Hou, Chin. J. Chem., 2012, 70, 436.
11 E. Zahedi, Superlattices Microstruct., 2011, 50, 491.

12 Z. Wengsieh, K. Cherrey, N. G. Chopra, X. Blase, Y. Miyamoto, A. Rubio, M. L. Cohen, S. G. Louie, A. Zettl and A. R. Gronsky, Phys. Rev. B: Condens. Matter Mater. Phys., 1995, 51, 11229.

13 L. Dai, Polym. Adv. Technol., 1999, 10, 357.

14 W. L. Wang, X. D. Bai, K. H. Liu, Z. Xu, D. Golberg, Y. Bando and E. G Wang, J. Am. Chem. Soc., 2006, 128, 6530.

15 O. Staphan, P. M. Ajayan, C. Colliex, Ph. Redlich, J. M. Lambert, P. Bernier and P. Lefin, Science, 1994, 266, 1683.

16 X. Blase, J.-C. Charlier, A. De Vita and R. Car, Appl. Phys. Lett., 1997, 70, 197.

17 Y. Miyamoto, A. Rubio, M. L. Cohen and S. G. Louie, Phys. Rev. B: Condens. Matter Mater. Phys., 1994, 50, 4976.

18 X. Blase, A. Rubio, S. G. Louie and M. L. Cohen, Phys. Rev. B: Condens. Matter Mater. Phys., 1995, 51, 6868.

19 K. Suenaga, C. Colliex, N. Demoncy, A. Loiseau, H. Pascard and F. Willaime, Science, 1997, 278, 653.

20 F. Piazza, J. E. Nocua, A. Hidalgo, J. De Jesus, R. Velazquez, B. L. Weiss and G. Morell, Diamond Relat. Mater., 2005, 14, 965.

21 P. Redlich, J. Loeffler, P. M. Ajayan, J. Bill, F. Aldinger and M. Riihle, Chem. Phys. Lett., 1996, 260, 465.

22 Y. Zhang, H. Gu, K. Seunaga and S. Iijima, Chem. Phys. Lett., 1997, 279, 264.

23 M. Terrones, A. M. Neneto, C. M. Diego, W. K. Hsu, O. I. Osman, J. P. Hare, D. G. Reid, H. Terrones, A. K. Cheetham, K. Prassides, H. W. Kroto and D. R. M. Walton, Chem. Phys. Lett., 1996, 257, 576.

24 W.-Q. Han, J. Cumings and A. Zettl, Appl. Phys. Lett., 2001, 78, 2769.

25 R. Sen, B. C. Satishkumar, A. Govindaraj, K. R. Harikumar, G. Raina, J. P. Zhang, A. K. Cheetham and C. N. R. Rao, Chem. Phys. Lett., 1998, 287, 671.

26 J. D. Guo, C. Y. Zhi, X. D. Bai and E. G. Wang, Appl. Phys. Lett., 2002, 80, 124.

27 R. M. Wang and H. Z. Zhang, New J. Phys., 2004, 6, 78.

28 J. Yu, J. Ahn, S. F. Yoon, Q. Zhang, R. B. Gan, K. Chew, M. B. Yu, X. D. Bai and E. G. Wang, Appl. Phys. Lett., 2000, 77, 1949.

29 C. Y. Zhi, J. D. Guo, X. D. Bai and E. G. Wang, J. Appl. Phys., 2002, 91, 5325.

30 S. Enouz-Vedrenne, O. Stephan, M. Glerup, J.-L. Cochon, C. Colliex and A. Loiseau, J. Phys. Chem. C, 2008, 112, 16422.

31 L. Liao, K. Liu, W. Wang, X. Bai, E. Wang, Y. Liu, J. Li and C. Liu, J. Am. Chem. Soc., 2007, 129, 9562.

32 S. Y. Kim, J. Park, H. Chul Choi, J. P. Ahn, J. Q. Hou and H. S. Kang, J. Am. Chem. Soc., 2007, 129, 1705.

33 W. Q. Han, J. Cumings, X. Huang, K. Bradley and A. Zettl, Chem. Phys. Lett., 2001, 346, 368.

34 M. Terrones, D. Golberg, N. Grobert, T. Seeser, M. ReyesReyes, M. Mayne, R. Kamalakaran, P. Dorozhkin, Z. C. Dong, H. Terrones, M. Ruhle and Y. Bando, Adv. Mater., 2003, 15, 1899. 
35 K. Raidongia, D. Jagadeesan, M. Upadhyay-Kahaly, U. V. Waghmare, S. K. Pati, M. Eswaramoorthy and C. N. R. Rao, J. Mater. Chem., 2008, 18, 83.

36 X. L. Wei, M. S. Wang, Y. Bando and D. Golberg, ACS Nano, 2011, 5, 2916.

37 J. Wu, W. Q. Han, W. Walukiewicz, J. W. Ager, W. Shan, E. E. Haller and A. Zettl, Nano Lett., 2004, 4, 647.

38 W. Q. Han, W. Mickelson, J. Cumings and A. Zettl, Appl. Phys. Lett., 2002, 81, 1110.

39 P. Ahmad, M. U. Khandaker, Z. R. Khan and Y. M. Amin, RSC Adv., 2015, 5, 35116.

40 A. Fathalizadeh, T. Pham, W. Mickelson and A. Zettl, Nano Lett., 2014, 14, 4881.

41 B. Huang, C. Si, H. Lee, L. Zhao, J. A. Wu, B. L. Gu and W. H. Duan, Appl. Phys. Lett., 2010, 97, 043115.

42 R. Y. Tay, H. L. Li, S. H. Tsang, L. Jing, D. L. Tan, M. W. Wei and E. H. T. Teo, Chem. Mater., 2015, 27, 7156.

43 X. Cui, W. Wei, C. Harrower and W. Chen, Carbon, 2009, 47, 3441.

44 L. Qin, J. Yu, S. Kuang, C. Xiao and X. Bai, Nanoscale, 2012, 4, 120.
45 L. B. Mo, Y. J. Chen and L. J. Luo, Appl. Phys. A: Mater. Sci. Process., 2010, 100, 129.

46 C. Y. Zhi, X. D. Bai and E. G. Wang, Appl. Phys. Lett., 2002, 80, 3590.

47 X. Yang, Z. Li, F. He, M. Liu, B. Bai, W. Liu, X. Qiu, H. Zhou, C. Li and Q. Dai, Small, 2015, 11, 3710.

48 G. Zhang, Z. Liu, L. Zhang, L. Jing and K. Shi, J. Chem. Sci, 2013, 125, 1169.

49 J. S. Zhou, N. Li, F. M. Gao, Y. F. Zhao, L. Hou and Z. M. Xu, Sci. Rep., 2014, 4, 6083.

50 A. Pakdel, X. Wang, C. Zhi, Y. Bando, K. Watanabe, T. Sekiguchi, T. Nakayama and D. Golberg, J. Mater. Chem., 2012, 22, 4818.

51 J. Tauc, R. Grigorov and A. Vancu, Phys. Status Solidi B, 1966, $15,627$.

52 B. K. Vijayan, N. M. Dimitrijevic, J. S. Wu and K. A. Gray, J. Phys. Chem. C, 2010, 114, 21262.

53 L. Ci, L. Song, C. H. Jin, D. Jariwala, D. X. Wu, Y. J. Li, A. Srivastava, Z. F. Wang, K. Storr, L. Balicas, F. Liu and P. M. Ajayan, Nat. Mater., 2010, 9, 430. 